\title{
Median Age of Medical Inpatients in a Tertiary Care Hospital
}

\author{
CHANDRA SHEKHAR BALA, ${ }^{1}$ SARMISTHA BISWAS, ${ }^{2}$ MD. MAHFUZE SARKAR ${ }^{3}$ PRODIP KUMAR SARKAR, ${ }^{4}$ \\ MAIMUNA SULTANA, ${ }^{4}$ MAHMUDA BEGUM,${ }^{4}$ JOYBAYER ANAM CHOWDHURY, ${ }^{5}$ BAHARUL MINNAT, ${ }^{6}$ HAM \\ NAZMUL AHASAN ${ }^{7}$
}

\begin{abstract}
:
Introduction: Population demography of the world including Bangladesh is on transition. The increasing number of elderly persons has a direct impact on the demand for health services due to the consequent rise in degenerative diseases of aging and changing life style. The chief objective was to know the median age of the medical inpatients.

Methods:This was an observational study. It was conducted in the wards of Medicine department of Dhaka Medical College Hospital from the I $^{\text {st }}$ of March to $15^{\text {th }}$ March.

Result: Median age of the admitted patients is 44.5 years. Highest admission is from the $6^{\text {th }}$ to $8^{\text {th }}$ decade of age group. A total of 176 patients (31.88\%) were above the ageof 60 years.

Discussion: Median age is one of the important measures of population aging. Global median age is 29 years whereas median age of Bangladeshi population is 22 years. The medianage of medical inpatients is relatively high. Percentage of patients aged more than 50 years are doubled in two decades.

Conclusion: It is evident that the face of patients in medicine wards is growing older. We must redistribute our resources to deal the conditions and diseases prevalent to the elderly people. We must be kept our preparedness up to date to serve the senior citizens.
\end{abstract}

Key Words: median age, elderly, geriatrics, inpatients.

\section{Introduction:}

Population demography of the world including Bangladesh is on transition. An increase of life expectancy, decline in fertility rates and decreasing mortality are the causes of increase in aging population. Such a rapid, large and ubiquitous growth has never been seen before in the history of civilization. This development is predicted to continue with an ever increasing number of elderly populations. The improvement in the health care system has raised the life expectancy from 36.6 to 67.7 over the last 40 years in Bangladesh. ${ }^{1}$

The increasing number of elderly persons has a direct impact on the demand for health services due to the consequent rise in degenerative diseases of aging and changing life style. Elderly people suffer from both communicable as well

1. Emergency Medical Officer, National Institute of Neurosciences and Hospital, Sher-E -Bangla Nagar, Dhaka

2. Assistant professor of Medicine, Dhaka Medical College, Dhaka.

3. Registrar, Medicine unit I, Dhaka Medical College Hospital (DMCH), Dhaka.

4. Indoor medical Officer, Medicine unit I, DMCH, Dhaka.

5. Assistant Registrar, Medicine unit I, DMCH, Dhaka.

6. State university of Bangladesh, Dhaka.

7. Professor of Medicine, Popular Medical College, Dhaka.

Correspondence: Dr. Chandra Shekhar Bala, Emergency Medical Officer, National Institute of neurosciences and Hospital, Sher-eBangla Nagar, Dhaka-1207. E-mail: arupsadhon@gmail.com. Contact: +08801714098855 as non-communicable diseases; further, this is compounded by impairment of sensory functions like vision, hearing, and instability management. Poor life style, decline in immunity as well as age-related physiologic changes lead to an increased burden of communicable diseases in the elderly. In the population over 70 years of age, more than $50 \%$ suffer from one or more chronic conditions. ${ }^{2}$

\section{Methods}

This was an observational study. It was conducted in the wards of Medicine department of Dhaka Medical College Hospital from the $1^{\text {st }}$ of March to $15^{\text {th }}$ March. We audited on the first post-admission day of Medicine Department. Internal Medicine department of Dhaka Medical College consists of 12 medicine units having similar structure and strength in terms of manpower, hospital beds and logistics.

We recorded demographic and clinical information of admitted patients of each unit. We analyzed the collected data in Windows Excel and SPSS.

\section{Result}

Total 552 patients admitted in the study period. Of them 286 patient were male (51.8\%) and 266 were female (48.2\%). The oldest patient was 90 years old and the youngest one was 13 years old. 176 patients $(31.88 \%)$ were over the age of 60 years. Median age of the admitted patients is 44.5 years. Highest admission is from the $6^{\text {th }}$ to $8^{\text {th }}$ decade of age group. A total of 253 patients $(45.8 \%)$ belong to the age group from 50 to 79 years. 


\section{Table-I}

Age distribution of admitted patients in medicine ward on first post admission day.

\begin{tabular}{lccc}
\hline Age range & Male & Female & Total \\
\hline$<20$ & 21 & 21 & 42 \\
$20-29$ & 40 & 37 & 77 \\
$30-39$ & 33 & 31 & 64 \\
$40-49$ & 46 & 55 & 101 \\
$50-59$ & 48 & 44 & 92 \\
$60-69$ & 69 & 49 & 118 \\
$70-79$ & 21 & 22 & 43 \\
$80-89$ & 07 & 07 & 14 \\
$90-99$ & 01 & 00 & 01 \\
Total & 286 & 266 & 552 \\
\hline
\end{tabular}

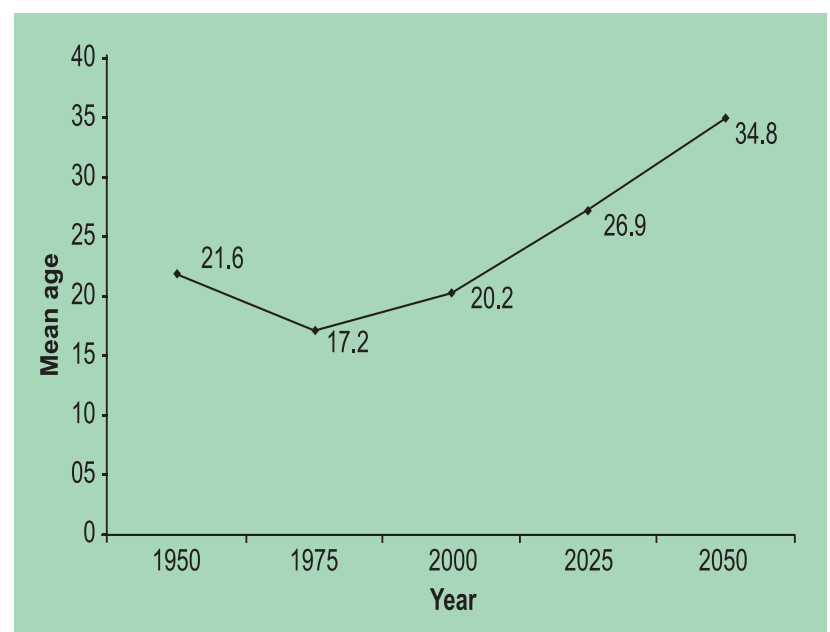

Fig.-1: Median age of Bangladesh (according to World Population Prospects 2009) ${ }^{6}$

Table-II

Bangladesh census 2011: projected population and percentage of population in elderly age group. ${ }^{1}$

\begin{tabular}{llll}
\hline Population (in million) (2011 Census) & Total & 14977 & BBS 2011 \\
\hline & Male & 74.98 & \\
& Female & 74.79 & \\
Population projected for July 2015 (In million) & Total & 158.96 & Bangladesh Data Sheet, BHS \\
& Male & 81.96 & \\
& Female & 7773 & \\
& & & \\
Population projected for July 2019 (In million) & Total & 167.39 & Bangladesh Data Sheet, BBS \\
& Male & 8 S.86 & \\
Sex ratio (male per 100 female) & Female & 81.51 & BBS 2011 \\
Population aged 0-14 years (both sexes In 96) & & 1007 & SVRS2010 \\
Female population (15-49 years In 96) & & 33.154 .367 & SVRS 2010 \\
Population (60+ years In 96) -both sexes & & 1015 & SVRS2010 \\
Papulation density per sq.km & & 67766.6 & Population \& House \\
& & 68.8 & hold Census 2011 \\
Life expectancy at birth (yean) & & & SVRS 2010 \\
& Both Sexes & & SVRS 2010 \\
& Male & & SVRS 2010 \\
\hline
\end{tabular}

\section{Discussion}

Median age is one of the significant measures of the population aging. It divides the population into older and younger halves. Other measures of population aging are

(a) Percentage of older people,

(b) The ageing index i.e. the ratio of the people aged 60 years or over to children under 15 years of age and (c) Old-age Dependency Ratio i.e. is the ratio of number of population aged 60 years and above per 100 working age (population aged 15-59 years) population. ${ }^{3}$

There has been considerable change in different aspects of life in last two decades in Bangladesh. For example Annual food production has increased 6 times, per capita income has raised to 1190 US Dollars. ${ }^{4}$ Population demography is on transition in Bangladesh as well. Life expectancy has 
increased from 36.6 years in $1950-1955$ to 60.7 years in 2000-2005, and is expected to rise to 75.0 years by the year 2045-2050. Life expectancy is 64 years as per 2011 population census. Approximately $6.7 \%$ of the population is aged over 60 years at present. By 2050 Median age may raise to 34.8 years with $16 \%$ of its population over the age of 60 years. Median age of population of Bangladesh is 22 years at present. ${ }^{1}$

Globally, the median age moved from 24 years in 1950 to 29 years in 2010, and will continue to increase to 36 years in 2050. United Nations has classified societies broadly into 'young' ( $4 \%$ or less of those aged $60+$ ), 'matured' (4-7\%) and "ageing" (7\% and above). In developed countries, the geriatric age group is taken as 65 years and above. Bangladesh is not yet included into the Aging population country according to the WHO definition till now. ${ }^{5}$

One common measure of population aging is the increase in the median age of its members. It is the figure below or above of which each half of the population lies. The median age of the population of Bangladesh, may increase by about 15 years over the next half century, i.e. 20.2 years in 2000 and 34.8 in $2050 .^{6}$

The chief objective of present study was to know the median age of the admitted patients in medicine ward so that we can focus the diseases and co morbidities of those age groups. We found that the median age of admitted patients was 44.5 years.

A study in Rajshahi Medical College Hospital revealed that $25 \%$ medical inpatients were above the age of 50 years from 1991 to 1993 . In contrast the present study shows that $48.55 \%$ medical inpatients are above the age of 50 years. ${ }^{7}$ This reflects the impact of changing population demographyon the health facilities.

Another observational study of patients admitted to an Internal Medicine service of the University Hospital of Valladolid, Spain was done in the year 1999. That revealed median age of admitted was 70 years. ${ }^{8}$

This is quite high in relation to our population demography. In addition the lowest age of admitted patients in adult ward of Bangladesh is 14years. This reflects the impact of transition of population demography. Certainly we have to deal the diseases and co morbidities prevalent to the middle and older age group more and more in near future. National Non Communicable Diseases risk factor survey conducted by Bangladesh Society of Medicine and funded by Directorate General of Health Services, Bangladesh and World Health Organization has revealed that $29 \%$ of adult population has 2 or more risk factors for Non Communicable Diseases risk. ${ }^{9}$ This is alarming. We have audited the co morbidities that are prevalent in medicine wards during the same time.

\section{Conclusion:}

It is evident that the face of patients in medicine wards is growing older due to increased life expectancy, decreased mortality rate and improved sanitation, social safety and health care network. Elderly people are asset of a nation. They can lead the progress of a nation forward with their knowledge and experience. We, the physicians must prepare ourselves and redistribute our national resources to deal the diseases and conditions prevalent to the elderly patients. Science has added years to life. It's our turn to add life to years.

\section{Conflict of Interest : None}

\section{References:}

1. National Institute of Population Research and Training (NIPORT), Mitra and Associates, and ICF International. 2013. Bangladesh Demographic and Health Survey 2011. Dhaka, Bangladesh and Calverton, Maryland, USA: NIPORT, Mitra and Associates, and ICF International. Page 2

2. Jaspinder K, Sargun S and Kawaljit K. Impact of Age on the Prevalence of Chronic Diseases in Geriatric Population. International Research Journal of Biological Sciences. 2014;3(9):79-85.

3. Gavrilov L.A., Heuveline P. "Aging of Population.”In: Paul Demeny and Geoffrey McNicoll (Eds.)The Encyclopedia of Population. New York, Macmillan Reference USA, 2003.

4. CPD: State of the Bangladesh Economy in Fiscal Year 2014 (Third Reading). 2014:5.

5. United Nations, Department of Economic and Social Affairs, Population Division (2013). World Population Ageing 2013. ST/ESA/SER.A/348

6. World Population prospects 2009.

7. AzharMA, Chowdhury MAJ, Ahasan HAMN, Rafiqueuddin AKM. Geriatric disease and geriatric problems amongst medical indoor patients. TAJ 1994;7:109-111.

8. Delgado Morales JL, Alonso del Busto R, Pascual Calleja I, Villacorta Martín MM, Ergueta Martín P, González Sarmiento E. Observational study of patients admitted to an Internal Medicine service. An Med Interna. 2004;21(1):3-6

9. Executive summary, page XXXVII, National NCD risk factor survey 2010 Report. 